\title{
Laser Cut Surface Roughness Modelling USING REGRESSION ANALYSIS
}

\author{
Mirza Pasic, Derzija Begic-Hajdarevic, Izet Bijelonja
}
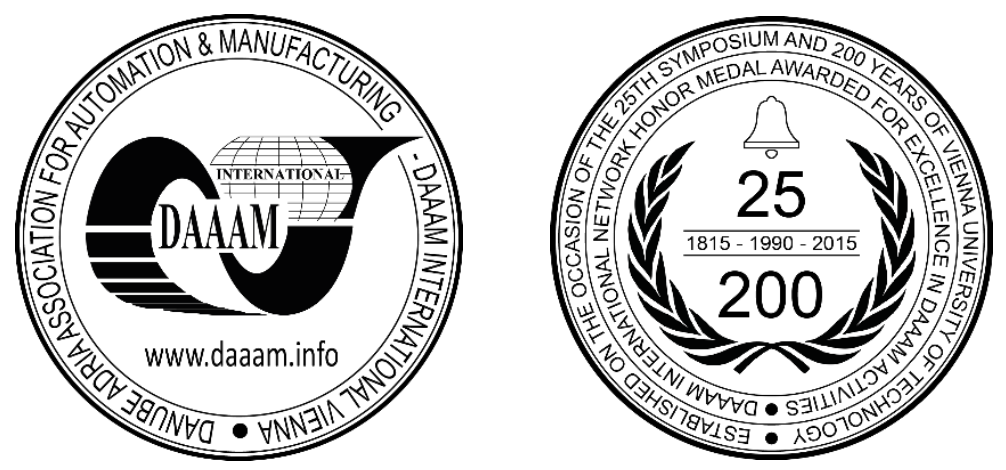

This Publication has to be referred as: Pasic, M[irza]; Begic-Hajdarevic, D[erzija] \& Bijelonja, I[zet] (2018). Laser Cut Surface Roughness Modelling Using Regression Analysis, Proceedings of the 29th DAAAM International Symposium, pp.0838-0845, B. Katalinic (Ed.), Published by DAAAM International, ISBN 978-3-902734-20-4, ISSN 1726-9679, Vienna, Austria

DOI: $10.2507 / 29$ th.daaam.proceedings.121

\begin{abstract}
In the modern industry the use of lasers has proven to be very useful due to the high precision and quality of cut. Important indicators of the cutting surface quality are roughness of the cutting surface $R_{a}$ and $R_{z}$. In this research experiment is performed to analyse the influence of laser power $P$, cutting speed $v$ and assist gas pressure $p$ as independent variables on dependent variables $R_{a}$ and $R_{z}$ during HSG fiber laser cutting of 1.4307 DIN stainless steel plates, $1 \mathrm{~mm}$ thick, using nitrogen as assist gas. During the experiment 75 samples are cut and 225 values of each cutting surface roughness $R_{a}$ and $R_{z}$ are measured. Data obtained during the experiment are analysed using regression analysis. Mathematical model is developed for each independent variable $R_{a}$ and $R_{z}$ depending on the significant independent variables. Surface roughness values $R_{z}$ are compared and analysed according to the quality categories defined by ISO 9013:2002 (E). It can be seen that regression analysis is good tool in modelling cutting surface quality $R_{a}$ and $R_{z}$.
\end{abstract}

Keywords: fiber laser cutting; surface roughness; regression; stainless steel plates; variables

\section{Introduction}

The increasing need for production of high precision parts involves higher usage of unconventional cutting methods like laser cutting. During laser cutting there is no physical contact with sample, but thermal energy is used for cutting. Due to high temperatures caused by this laser cutting thermal process, material is melted and then removed by assist gas. Although laser cutting is very precise technique, influence of cutting parameters on surface roughness remains major research problem. For different materials it is important to provide optimal cutting parameters.

Statistical control charts were used to analyse influence of cutting parameters on surface roughness [1]. Lower laser power and higher cutting speed lead to weakening of process control status of tungsten alloy using nitrogen as assist gas. The influence of cutting parameters on cut perpendicularity during HSG fiber laser cutting of stainless steel 1.4307 DIN, $1 \mathrm{~mm}$ thick, using linear regression analysis was analysed in [2], since cut perpendicularity is important aspect of cutting surface quality. Mathematical model was developed using linear regression analysis. The model shows that the cutting speed is the only significant independent variable in the model and that the values of cut perpendicularity increase with the increase of cutting speed values. 
The correlation between cutting speed and heat affected zone and surface roughness during laser cutting, of 316L stainless steel was discussed in [3]. It is shown that the increase of cutting speed increases quality of surface roughness and very low heat affected zone. In [4] ANOVA was applied to analyse surface roughness and top kerf width based on influence of laser power, cutting speed and gas pressure. Stainless steel (ASTM 304), 3 mm of thickness, was used in this experiment. The lowest surface roughness values were obtained having the lowest laser power and gas pressure and with the highest cutting speed [4]. Investigation of impact of use oxygen, air and nitrogen as assist gas and assist gas pressure on sourface roughness, heat affected zone and kerf width was done in [5]. Nitrogen as assist gas was recommended for laser cutting process since it produced best experimental results of three quality cutting process characteristics. However, for each quality characteristcs different assist gas pressures were recommended.

Research [6] showed effect of laser cutting parameters during $\mathrm{CO}_{2}$ laser cutting polymethylmethacrylate $6 \mathrm{~mm}$ thick, on surface roughness and optical transmittance ratio using grey relational analysis method. Flow rate of assist gas and beam focus depth are the most influential factors of the surface cut quality. Evaluation of the cut quality based on surface roughness, shape and width of the cut, heat affected zone and burr was done in [7] using metallographic methods during $\mathrm{CO}_{2}$ laser cutting of INCONEL 625 alloy. It was suggested to increase inert gas pressure, decrease distance of the nozzle and decrease movement speed on the parts where there are changes in the shape. Surface roughness was analysed in [8] during abrasive water jet machining on two different carbon fiber reinforced plastics using regression analysis. ANOVA and $\mathrm{F}$ test showed that the most important parameters that affect surface roughness are jet pressure, standoff distance and traverse speed [8].

In this paper surface roughness values $R_{a}$ and $R_{z}$ during HSG fiber laser cutting were analysed using regression analysis. Independent variables were laser power $P$, cutting speed $v$ and assist gas pressure $p$. Obtained experimental values of $R_{z}$ were compared to quality groups according to ISO 9013:2002 (E) standard.

\section{2. xperimental setup}

This experiment was aimed to establish the effect of laser power $P$, cutting speed $v$ and assist gas pressure $p$ on the surface roughness $R_{a}$ and $R_{z}$ for 1.4307 DIN stainless steel (X2CrNi18-9) $1 \mathrm{~mm}$ thick after the laser cutting process on HSG fiber laser. The laser model was the HS - G3015A with the maximum power of $1000 \mathrm{~W}$. The constant cutting parameters during the experiment were: focus position, type of assist gas and the distance between the nozzle and the cutting surface. The focus position was $F P=-1 \mathrm{~mm}$, the nozzle distance was $1 \mathrm{~mm}$ and the diameter of the nozzle $D M L=1,5 \mathrm{~mm}$. The assist gas used in the experiment was nitrogen $\left(N_{2}\right)$.

During the experiment, 75 samples were cut. Dimensions of the samples were 100x60x1 (mm). For each combination of 5 laser power values, 5 cutting speed values and 3 gas pressure values, one sample was cut. After the laser cutting process, roughness of the surface on each piece was measured. The roughness is measured on the Surftest SJ - 210 Mitutoyo roughness measuring device on all 75 samples. Three places along the cut were selected on each sample and $R_{a}$ and $R_{z}$ were measured. On each of 75 samples, three measurements were performed, so that a total of 225 values of $R_{a}$ and 225 values of $R_{z}$ were measured. After the values of $R_{a}$ and $R_{z}$ were measured, the dependences of the values of $R_{a}$ and $R_{z}$ on the laser power $P$, the cutting speed $v$ and the assist gas pressure $p$ were analysed. In the end, the measured values of $R_{z}$ were compared with the quality categories according to ISO 9013: 2002 (E).

\section{Result analysis}

Three scatter plots of relationship between $R_{a}$ and three independent variables $(P, v, p)$ are depicted at figure 1 , figure 2 and figure 3 respectively.

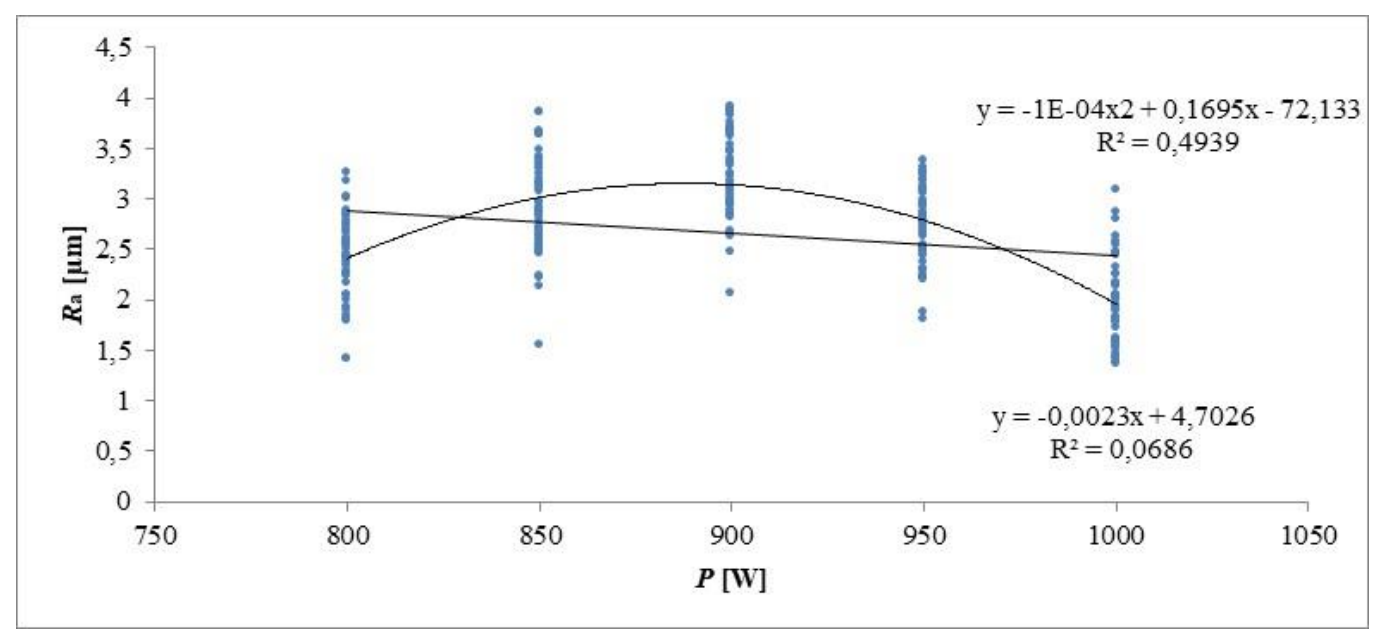

Fig. 1. Relationship between $R_{a}$ and independent variable $P$ 


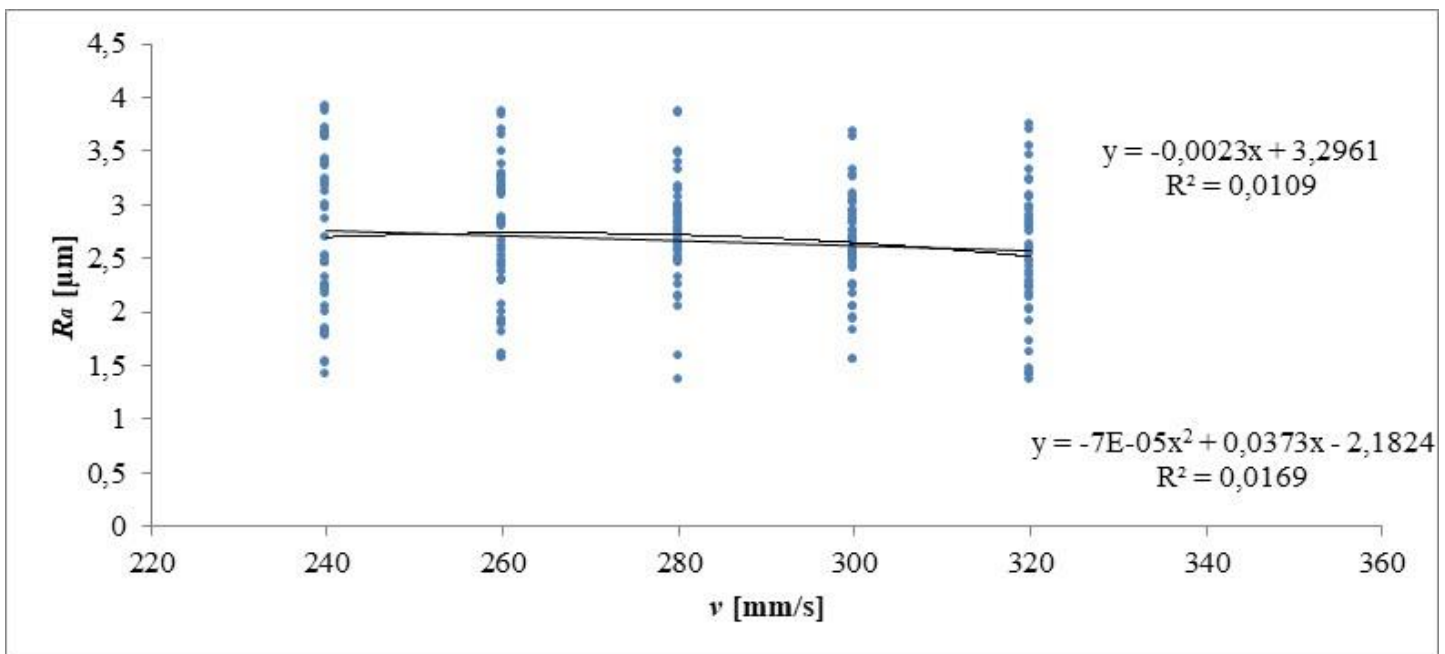

Fig. 2. Relationship between $R_{a}$ and independent variable $v$

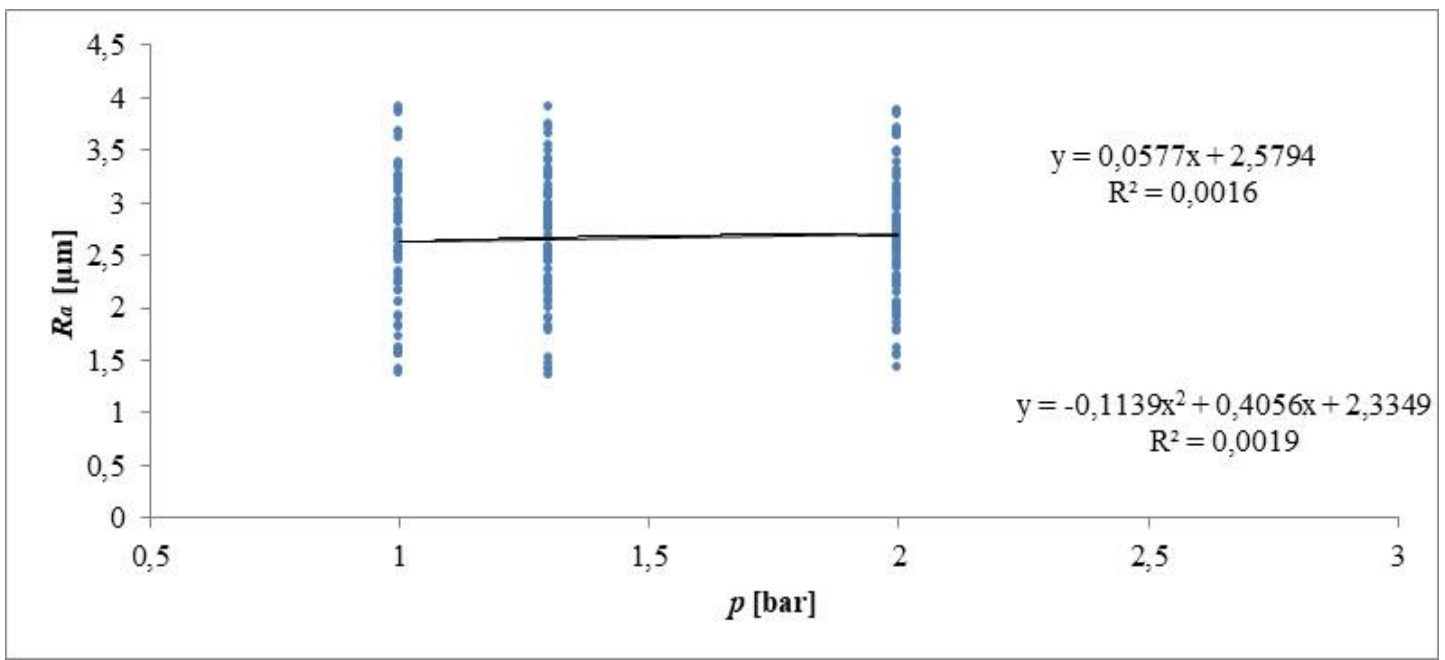

Fig. 3. Relationship between $R_{a}$ and independent variable $p$

From above figures it can be seen that variablity of velocity and pressure do not contribute much to the variablity of $R_{a}$, while nonlinear quadratic pattern of relationship between $R_{a}$ and laser power $P$ can be observed. Relationship between $R_{z}$ and three independent variables $(P, v, p)$ are depicted at scatter plots at figure 4, figure 5 and figure 6 respectively.

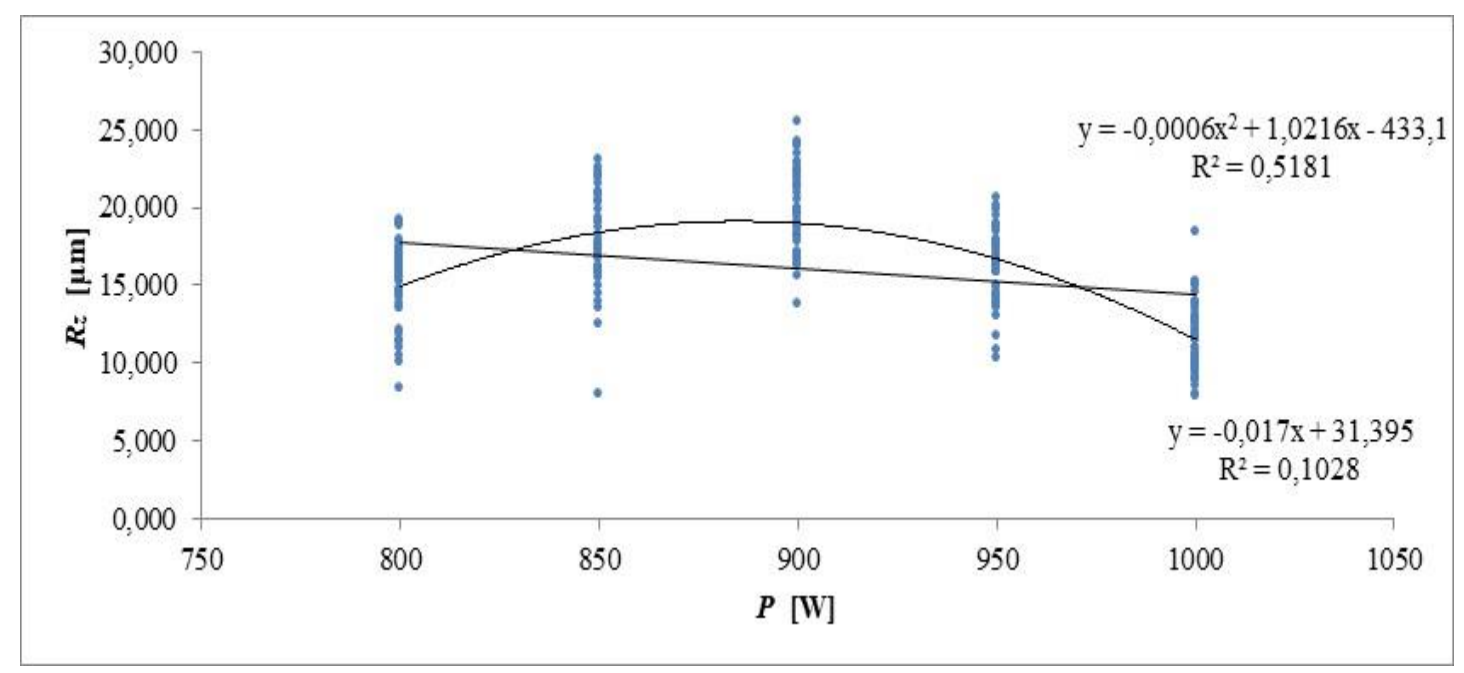

Fig. 4. Relationship between $R_{Z}$ and independent variable $P$ 


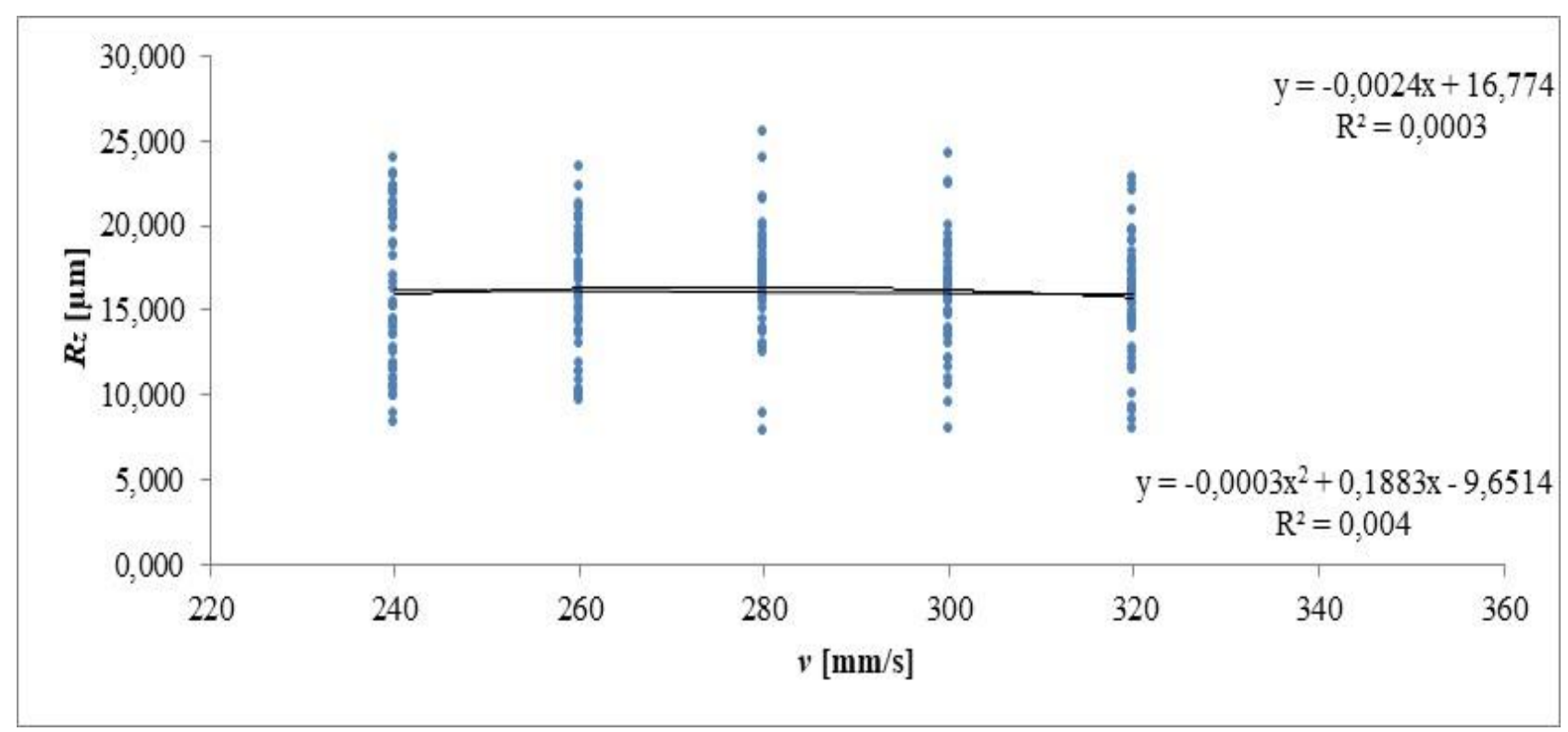

Fig. 5. Relationship between $R_{z}$ and independent variable v

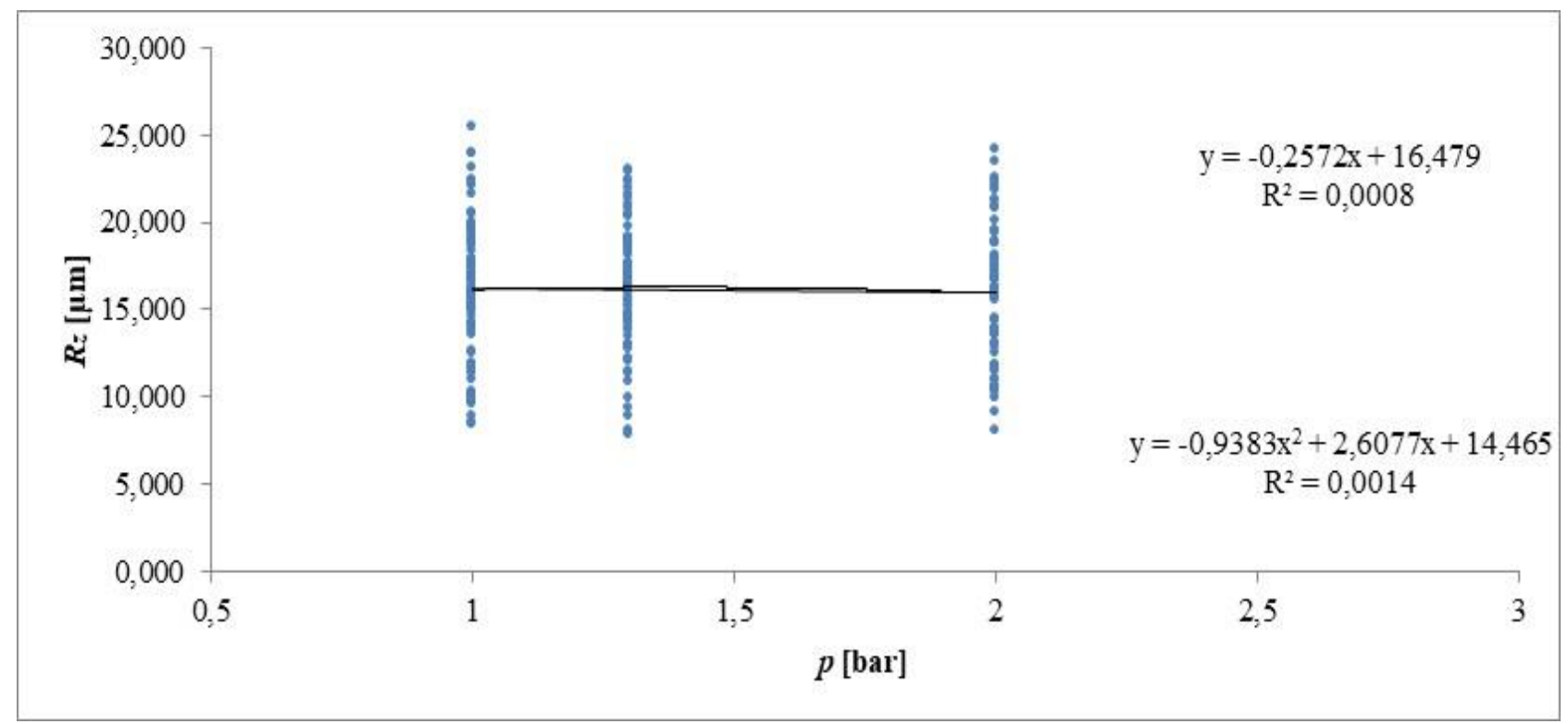

Fig. 6. Relationship between $R_{z}$ and independent variable $p$

Above scatter plots show that variablity of velocity and pressure do not contribute much to the variablity of $R_{z}$ as well. It can be seen that there is nonlinear quadratic pattern of relationship between $R_{z}$ and laser power $P$.

Existance of nonlinear quadratic relationships was the main reason for the use of quadratic regression analysis in this research. The basic form of quadratic regression equation with three independent variables including quadratic, linear and interaction terms is shown in (1).

$$
\begin{gathered}
y=b_{0}+b_{1} \cdot x_{1}+b_{2} \cdot x_{2}+b_{3} \cdot x_{3}+b_{4} \cdot x_{1} \cdot x_{2}+b_{5} \cdot x_{1} \cdot x_{3}+b_{6} \cdot x_{2} \cdot x_{3}+b_{7} \cdot x_{1}^{2}+b_{8} \cdot x_{2}^{2}+b_{9} \cdot x_{3}^{2}+b_{10} \cdot x_{1} \cdot x_{2} \\
\cdot x_{3}
\end{gathered}
$$

Backward regression analysis is used in this analysis. Because of large number of steps during the backward regression analysis only the first and the final regression models are shown in this paper.

Regression analysis results for $R_{a}$ are depicted in table 1 . 
SUMMARY OUTPUT

\begin{tabular}{lc}
\hline Regression Statistics & \\
\hline Multiple R & 0,721 \\
R Square & 0,520 \\
Adjusted R Square & 0,498 \\
Standard Error & 0,435 \\
Observations & 225 \\
\hline
\end{tabular}

\begin{tabular}{|c|c|c|c|c|c|c|}
\hline \multicolumn{7}{|l|}{ ANOVA } \\
\hline & $\mathrm{df}$ & SS & MS & $\mathrm{F}$ & Significance $\mathrm{F}$ & \\
\hline Regression & 10 & 43,887 & 4,389 & 23,222 & 0,000 & \\
\hline Residual & 214 & 40,444 & 0,189 & & & \\
\hline \multirow[t]{2}{*}{ Total } & 224 & 84,331 & & & & \\
\hline & Coefficients & Standard Error & t Stat & $\mathrm{P}$-value & Lower 95\% & Upper $95 \%$ \\
\hline Intercept & $-96,369$ & 14,662 & $-6,573$ & 0,000 & $-125,270$ & $-67,468$ \\
\hline $\mathrm{P}$ & 0,191 & 0,019 & 9,990 & 0,000 & 0,154 & 0,229 \\
\hline $\mathrm{v}$ & 0,106 & 0,053 & 2,017 & 0,045 & 0,002 & 0,210 \\
\hline $\mathrm{p}$ & 14,799 & 8,835 & 1,675 & 0,095 & $-2,614$ & 32,213 \\
\hline $\mathrm{P}$ sq & 0,000 & 0,000 & $-13,777$ & 0,000 & 0,000 & 0,000 \\
\hline v sq & 0,000 & 0,000 & $-1,630$ & 0,104 & 0,000 & 0,000 \\
\hline $\mathrm{p}$ sq & $-0,114$ & 0,300 & $-0,379$ & 0,705 & $-0,706$ & 0,478 \\
\hline $\mathrm{P} * \mathrm{v}$ & 0,000 & 0,000 & $-1,520$ & 0,130 & 0,000 & 0,000 \\
\hline $\mathrm{P} * \mathrm{p}$ & $-0,016$ & 0,010 & $-1,687$ & 0,093 & $-0,036$ & 0,003 \\
\hline $\mathrm{v}^{*} \mathrm{p}$ & $-0,052$ & 0,031 & $-1,661$ & 0,098 & $-0,113$ & 0,010 \\
\hline$\underline{\mathrm{P} * \mathrm{v} * \mathrm{p}}$ & 0,000 & 0,000 & 1,710 & 0,089 & 0,000 & 0,000 \\
\hline
\end{tabular}

Table 1. First results of regression analysis for $R_{a}$

For significance level $\alpha=0,05$ with 10 and 214 degress of freedom $F_{\text {crit }}=1,87$. Since $F_{\text {stat }}=23,22>F_{\text {crit }}$ it can be concluded that at least one regression coefficient is different from zero. Using t-test all coefficients that are not significantly different from zero are observed and variable with the lowest apsolute value of $t_{\text {stat }}$ is excluded from the model. These steps are repeated until all non-significant variables are exluded from the model. The final regression model is shown in table 2 .

\section{SUMMARY OUTPUT}

\begin{tabular}{lc}
\hline Regression Statistics & \\
\hline Multiple R & 0,711 \\
R Square & 0,506 \\
Adjusted R Square & 0,499 \\
Standard Error & 0,434 \\
Observations & 225 \\
\hline
\end{tabular}

\begin{tabular}{|c|c|c|c|c|c|c|}
\hline \multicolumn{6}{|l|}{ ANOVA } & \\
\hline & $\mathrm{df}$ & SS & MS & $\mathrm{F}$ & Significance $\mathrm{F}$ & \\
\hline Regression & 3 & 42,633 & 14,211 & 75,319 & 0,000 & \\
\hline Residual & 221 & 41,698 & 0,189 & & & \\
\hline \multirow[t]{2}{*}{ Total } & 224 & 84,331 & & & & \\
\hline & Coefficients & Standard Erro1 & t Stat & $\mathrm{P}$-value & Lower 95\% & Upper $95 \%$ \\
\hline Intercept & $-71,803$ & 5,587 & $-12,853$ & 0,000 & $-82,813$ & $-60,793$ \\
\hline $\mathrm{P}$ & 0,170 & 0,012 & 13,599 & 0,000 & 0,145 & 0,194 \\
\hline $\mathrm{P}^{\wedge} 2$ & 0,000 & 0,000 & $-13,788$ & 0,000 & 0,000 & 0,000 \\
\hline$v^{\wedge} 2$ & 0,000 & 0,000 & $-2,278$ & 0,024 & 0,000 & 0,000 \\
\hline
\end{tabular}

Table 2. Final results of regression analysis for $R_{a}$

Final regression model shows that laser power $P$ and cutting speed $v$ are significant variables. The final quadratic regression equation is shown by (2).

$$
R_{a}=-71,803-0,0000954 \cdot P^{2}+0,1695386 \cdot P-0,0000042 \cdot v^{2}
$$


The same steps were applied during $R_{z}$ analysis. In table 3 are shown the results of regression analysis for $R_{z}$.

\section{SUMMARY OUTPUT}

\begin{tabular}{lc}
\hline Regression Statistics & \\
\hline Multiple R & 0,726 \\
R Square & 0,527 \\
Adjusted R Square & 0,505 \\
Standard Error & 2,640 \\
Observations & 225 \\
\hline
\end{tabular}

\begin{tabular}{lccccc} 
ANOVA & df & SS & MS & F & Significance F \\
\hline Regression & 10 & 1664,691 & 166,469 & 23,883 & 0,000 \\
Residual & 214 & 1491,648 & 6,970 & & \\
Total & 224 & 3156,340 & & & \\
\hline
\end{tabular}

\begin{tabular}{lcccccc}
\hline & Coefficients & Standard Erro1 & t Stat & P-value & L ower 95\% & Upper 95\% \\
\hline Intercept & $-550,931$ & 89,045 & $-6,187$ & 0,000 & $-726,449$ & $-375,413$ \\
$\mathrm{P}$ & 1,125 & 0,116 & 9,675 & 0,000 & 0,896 & 1,355 \\
$\mathrm{v}$ & 0,518 & 0,319 & 1,622 & 0,106 & $-0,112$ & 1,147 \\
$\mathrm{p}$ & 59,540 & 53,653 & 1,110 & 0,268 & $-46,215$ & 165,296 \\
$\mathrm{P}^{\wedge} 2$ & $-0,001$ & 0,000 & $-13,714$ & 0,000 & $-0,001$ & 0,000 \\
$\mathrm{v}^{\wedge} 2$ & 0,000 & 0,000 & $-1,295$ & 0,197 & $-0,001$ & 0,000 \\
$\mathrm{p}^{\wedge} 2$ & $-0,938$ & 1,825 & $-0,514$ & 0,608 & $-4,535$ & 2,658 \\
$\mathrm{P}^{*} \mathrm{v}$ & 0,000 & 0,000 & $-1,203$ & 0,230 & $-0,001$ & 0,000 \\
$\mathrm{P}^{*} \mathrm{p}$ & $-0,065$ & 0,059 & $-1,108$ & 0,269 & $-0,182$ & 0,051 \\
$\mathrm{v}^{*} \mathrm{p}$ & $-0,208$ & 0,190 & $-1,095$ & 0,275 & $-0,581$ & 0,166 \\
$\mathrm{P}^{*} \mathrm{v}^{*} \mathrm{p}$ & 0,000 & 0,000 & 1,137 & 0,257 & 0,000 & 0,001 \\
\hline
\end{tabular}

Table 3. First results of regression analysis for $R_{z}$

After $F$ test $\left(F_{\text {stat }}=23,833>F_{\text {crit }}=119,359\right)$ and t-test, it was concluded that there were coefficients that were not significantly different from zero and the one with the lowest apsolute value of $t_{\text {stat }}$ was excluded from the model. The procedure was continued until all non-significant variables were exluded from the model. The final results of the regression analysis for $R_{z}$ are shown in table 4 .

\section{SUMMARY OUTPUT}

\begin{tabular}{lr}
\hline \multicolumn{2}{c}{ Regression Statistics } \\
\hline Multiple R & 0,720 \\
R Square & 0,518 \\
Adjusted R Square & 0,514 \\
Standard Error & 2,617 \\
Observations & 225 \\
\hline
\end{tabular}

ANOVA

\begin{tabular}{|c|c|c|c|c|c|}
\hline & df & SS & $\mathrm{MS}$ & $\mathrm{F}$ & Significance F \\
\hline Regression & 2 & 1635,435 & 817,717 & 119,359 & 0,000 \\
\hline Residual & 222 & 1520,905 & 6,851 & & \\
\hline Total & 224 & 3156,340 & & & \\
\hline
\end{tabular}

\begin{tabular}{lrrrrrr}
\hline & Coefficients & Standard Error & \multicolumn{1}{c}{ t Stat } & P-value & Lower 95\% & Upper 95\% \\
\hline Intercept & $-433,096$ & 33,652 & $-12,870$ & 0,000 & $-499,415$ & $-366,778$ \\
$\mathrm{P}$ & 1,022 & 0,075 & 13,600 & 0,000 & 0,874 & 1,170 \\
$\mathrm{P}^{\wedge} 2$ & $-0,001$ & 0,000 & $-13,833$ & 0,000 & $-0,001$ & 0,000 \\
\hline
\end{tabular}

Table 4. Final results of regression analysis for $R_{z}$ 
After the backward quadratic regression analysis it can be concluded that the only significant variable for $R_{z}$ is laser power $P$. The final model for $R_{z}$ is shown in (3).

$$
R_{z}=-433,096+1,0216315 \cdot P^{2}-0,0005770 \cdot P
$$

Figures 7, 8 and 9 show diagrams of residuals, stadardised residuals and histogram of residuals for $R_{a}$ and $R_{z}$ respectively.

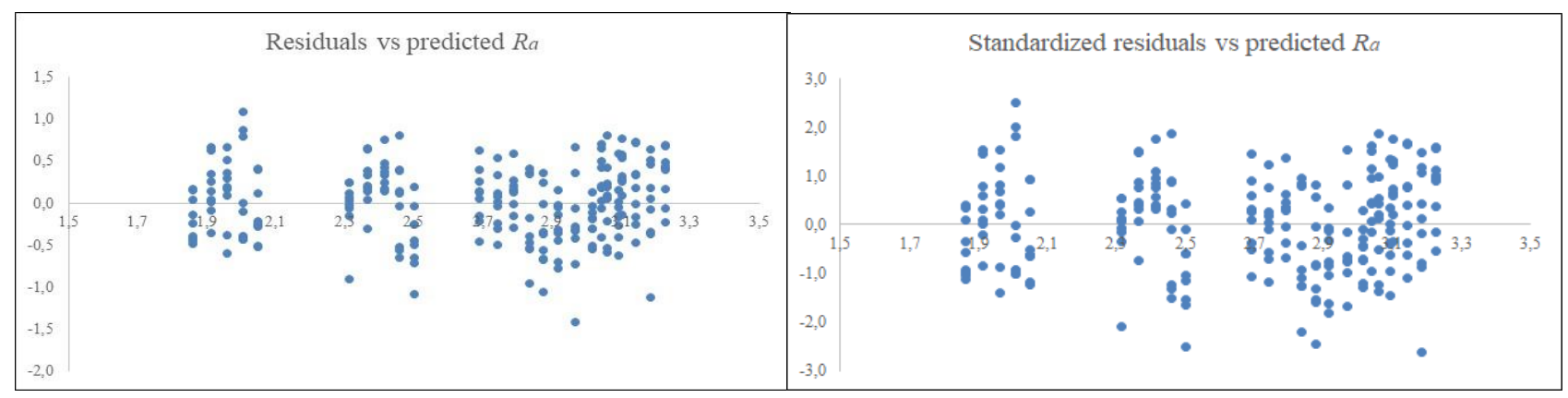

Fig. 7. Residuals vs predicted $R_{a}$ and standardized residuals vs predicted $R_{a}$

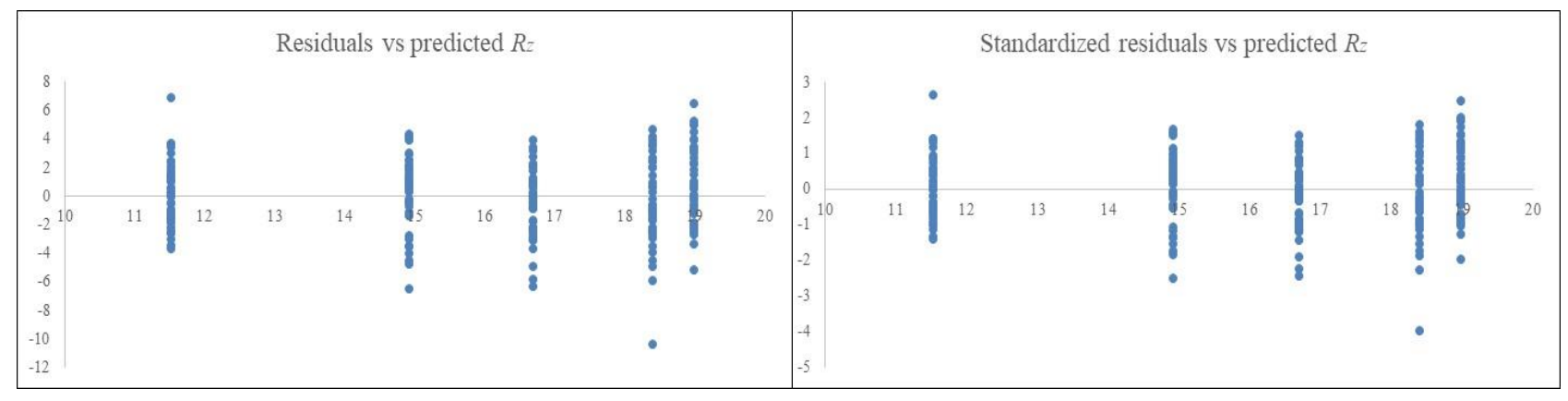

Fig. 8. Residuals vs predicted $R_{z}$ and standardized residuals vs predicted $R_{Z}$

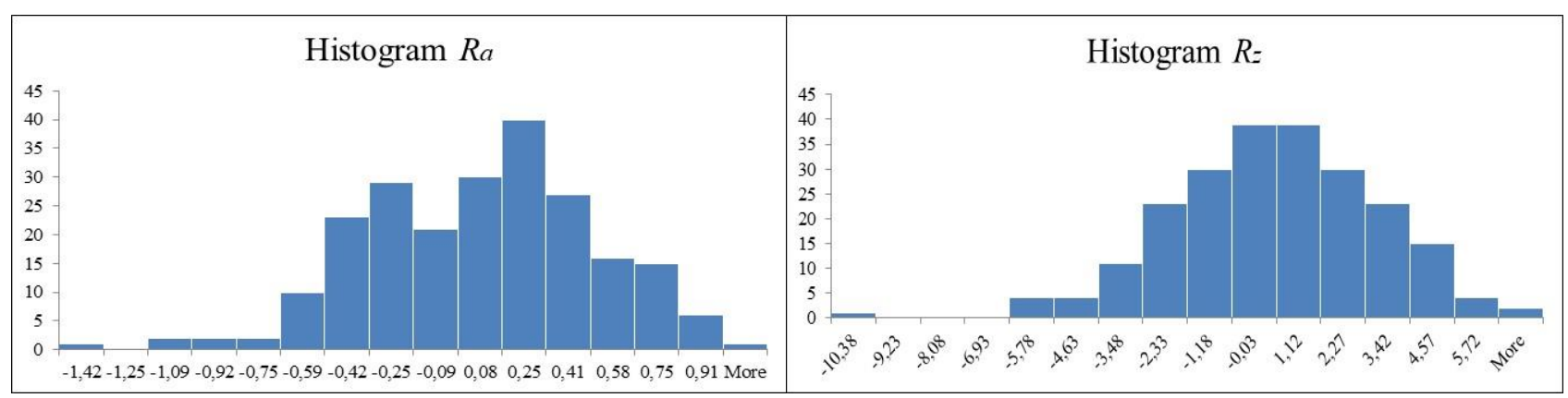

Fig. 9. Histogram $R_{a}$ and histogram $R_{Z}$

Figures 7 and 8 show that residual values are located around zero and that there is no visible pattern and that standardized residuals values are within three standard deviations. It can be concluded that quadratic regression analysis is appropriate to create model for $R_{a}$ and $R_{z}$. Figure 9 shows that the residuals are approximately normally distributed. The condition of normality of residuals is satisfied.

\section{Comparison of $R_{z}$ values with ISO standard}

There are 225 values of $R_{z}$ that were measured during the experiment. Those values were compared to the quality category groups defined by ISO 9013: 2002 (E) standard. Figure 10 shows that the most of the values of $R_{z}$ are in the second quality group according to ISO standard. But some of the values are in the first quality group.

Those values were obtained for laser power $P=800 \mathrm{~W}$ and $P=1000 \mathrm{~W}$. 


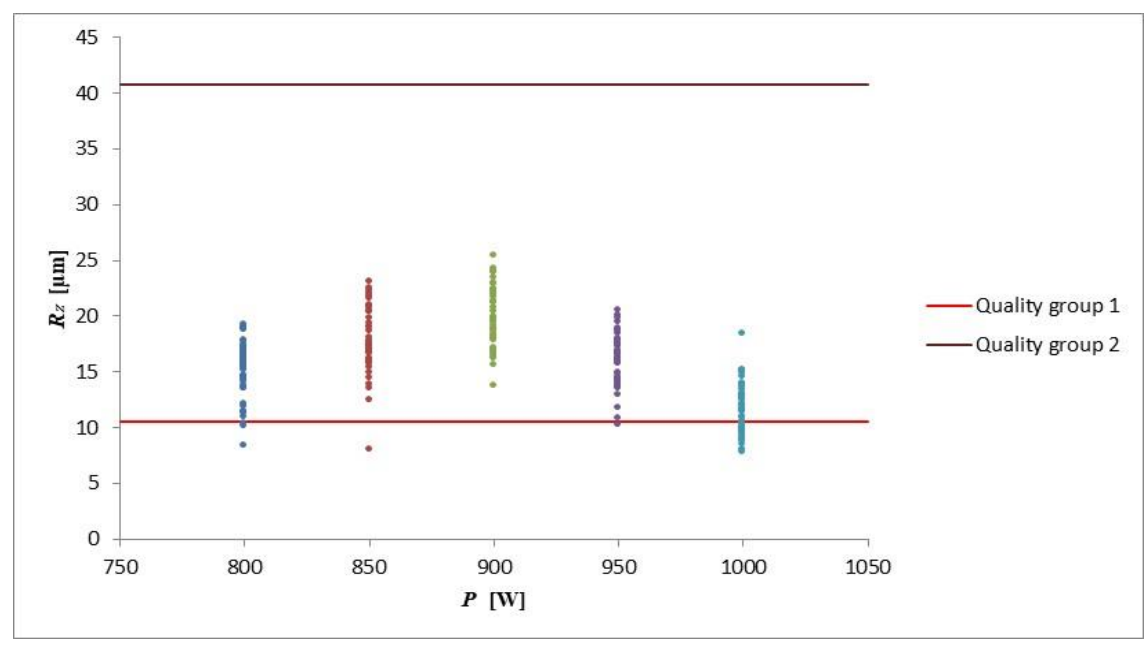

Fig. 10. $R_{z}$ values

\section{Conclusion}

Since the surface roughness parameters $R_{a}$ and $R_{z}$ in laser cutting are very important, the influence of cutting parameters such as laser power, cutting speed and assist gas pressure on $R_{a}$ and $R_{z}$ during laser cutting on HSG fiber laser of stainless steel 1.4307 DIN was investigated. In order to examine the dependence of $R_{a}$ and $R_{z}$ on the mentioned cutting parameters, a quadratic regression analysis was used. Analysis shows that significant independent variables for $R_{a}$ are laser power $P$ and cutting speed $v$ and for $R_{z}$ it is laser power $P$. From the quadratic equations obtained through regression analysis, it can be concluded that the values of $R_{a}$ and $R_{z}$ are lower if the values of laser power $P$ are at minimum value $(800 \mathrm{~W})$ and at maximum value $(1000 \mathrm{~W})$. Also, at lower values of cutting speed, value of $R_{a}$ will be lower. The influence of the cutting speed $v$ is much lower than the influence of the laser power $P$ on the values of $R_{a}$. Also, assist gas pressure is not significant variable for both $R_{a}$ and $R_{z}$. The comparison of values of $R_{z}$ with the the quality category groups defined by ISO 9013: 2002 (E) standard was done. Comparison shows that the most values of $R_{z}$ are in the second quality group according to ISO standard. It can be concluded that the highest chance to have the value $R_{z}$ in the first quality group is by setting the laser power to $800 \mathrm{~W}$ or $1000 \mathrm{~W}$. The highest quality of the cutting surface can be achieved with the laser power of $800 \mathrm{~W}$ and $1000 \mathrm{~W}$ and with the lower values of cutting speed $v$. In the future research experiment the same combination of the cutting parameters will be used to predict the values of heat affected zone using regression analysis.

\section{References}

[1] Begic-Hajdarevic, D.; Vucijak, B.; Pasic, M. \& Bijelonja, I. (2017). Analysis of the influence of cutting parameters on surface roughness in laser cutting process of tungsten alloy using control charts. Technical gazette, 24, Vol. 2, (2017) page numbers (339-344), ISSn 1330-3651 (Print), ISSN 1848-6339 (Online)

[2] Pasic, M.; Begic-Hajdarevic D. \& Bijelonja, I. (2017). Estimation of the laser cut prependicularity using linear regression analysis, Proceedings of the 28th DAAAM International Symposium, ISSN 1726-9679, ISBN 978-3902734, Katalinic, B. (Ed.), pp. 1083-1089, DAAAM International, Vienna, DOI: 10.2507/ 28th.daaam.proceedings. 150

[3] Jarosz, K.; Löschner, P. \& Nieslony, P. (2016). Effect of cutting speed on surface quality and heat-affected zone in laser cutting of 316L stainless steel, Procedia Engineering, Vol. 149, page numbers (155-162), ISSN 1877-7058

[4] Kotadiya, J. D.; Kapopara, M. J.; Patel, R. A.; Dalwadi, G. C. \& Pandya, H. D. (2018). Parametric analysis of process parameter for Laser cutting process on SS-304. Materials Today: Proceedings, Vol. 5, (2018) page numbers (53845390), ISSN 2214-7853

[5] Begic-Hajdarevic, D.; Pasic, M.; Cekic, A. \& Mehmedovic, M. (2016). Optimization of process parameters for cut quality in $\mathrm{CO}_{2}$ laser cutting using Taguchi method, Proceedings of 27th DAAAM International Syposium, ISSN 1726-9679; ISBN 978-3-902734-08-2, Katalinic, B. (Ed), pp. 0157-0164, DAAAM International, Vienna, DOI: 10.2507/27th.daaam.proceedings.024

[6] Chen, M.-F.; Ho, Y.-S.; Hsiao, W.-T.; Wu, T.-H.; Tseng, S.F. \& Huang,K.-C. (2011). Optimized laser cutting on light guide plates using grey relational analysis. Optics and Lasers in Engineering, Vol. 49, (2011) page numbers (222-228), ISSN 0143-8166

[7] Grepl, M.; Petru, J.; Cep, R.; Petrkovska, L. \& Zlamal, T. (2012). The effect of process parameters on result quality of cut during laser cutting of material, Proceedings of the 23th DAAAM International Symposium, ISSN 23041382, ISBN 978-3-901509-91-9, Katalinic, B. (Ed.), pp. 1035-1038, DAAAM International, Vienna

[8] Kumaran, S. T.; Ko, T. J.; Uthayakumar, M. \& Islam, M. M. (2017). Prediciotn of surface roughness in abrasive water jet machining of CFRP composites using regression analysis. Journal of Alloys and Compounds, Vol. 724 (15 November 2017), page numbers (1037-1045), ISSN 0935-8388 